\title{
Utility of a Plumber - HANARO stent in pyloric stenosis after circumferential ESD
}

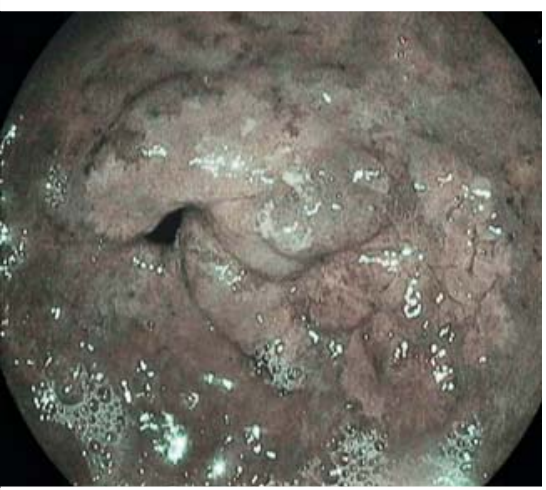

> Fig. 1 Lesion

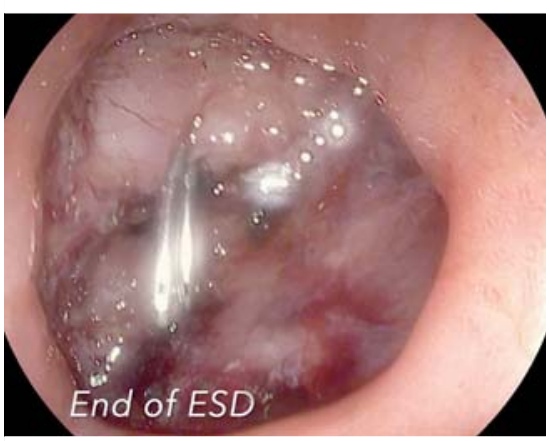

> Fig. 2 Post-ESD image

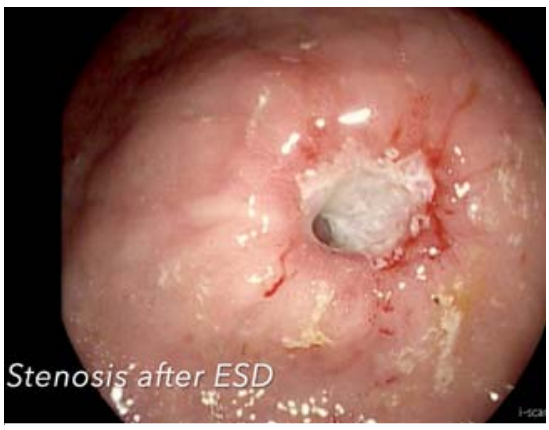

$\checkmark$ Fig. 3 Stenosis

\section{Introduction}

On endoscopy, a 71-year-old man suffering from chronic, severe atrophic gastropathy, with areas of massive complete intestinal metaplasia presented with a 35-mm stage lla/b nongranular, laterally sreading tumor ( $>$ Fig. 1 ). It was narrow

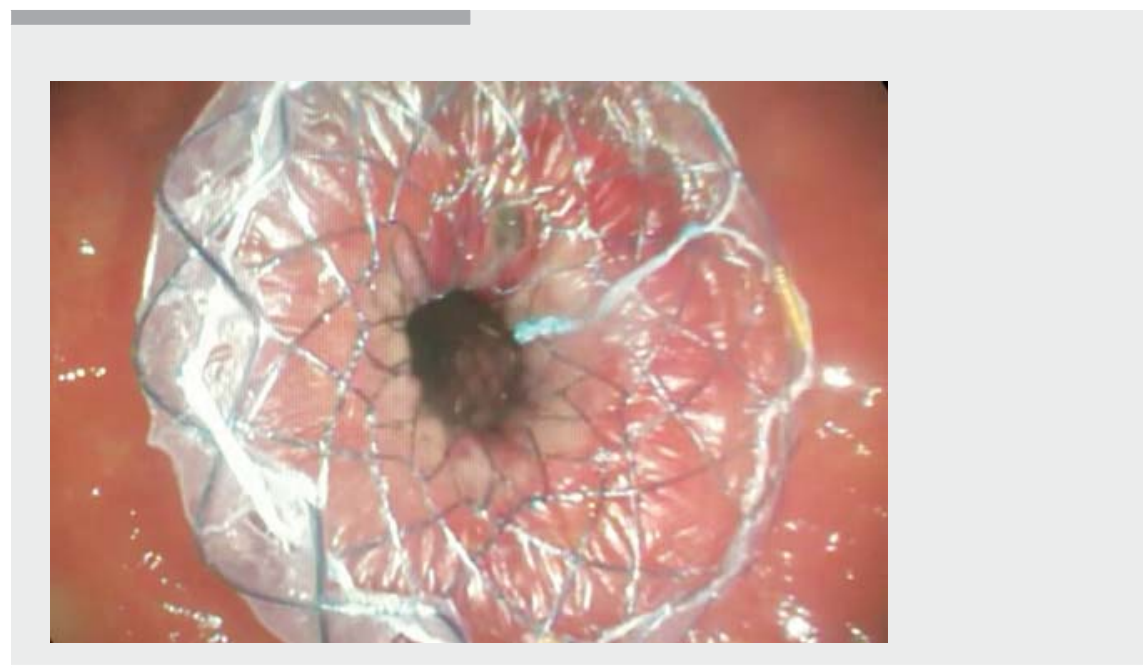

$\triangle$ Video 1 Stenosis after ESD. Stent placement.

band imaging international colorectal endoscopic classification 2 and had a type VI pit pattern and affected $70 \%$ of the circumference of the pylorus and extended through the antrum towards the greater curvature. Biopsies of the lesion showed a tubular adenoma with lowgrade dysplasia, which prompted the decision to perform DSE.

\section{Endoscopy}

Endoscopic submucosal dissection (ESD) was performed and an en-bloc specimen measuing $52 \times 38 \times 5 \mathrm{~mm}$ was obtained ( Fig.2). Histologic examination revealed chronic, moderate atrophic gastropathy with intestinal metaplasia and extensive areas of low- and high-grade intraepithelial neoplasia. The lateral and deep margins were disease-free ( $\vee \mathbf{V i -}$ deo 1 ).

At 3 weeks after ESD, the patient presented with symptoms of pyloric stenosis and the diagnosis was confirmed endoscopically by observation of a short, puntiform pyloric stenosis (10 mm) ( $\triangleright$ Fig.3). Three sequential dilations were performed with a CRE balloon up to $18 \mathrm{~mm}$ with early restenosis on all occasions and with a progressive weight loss up to $12 \mathrm{~kg}$. Finally, a $16-\times 30-\mathrm{mm}$ fully-covered metallic stent (Plumber HANAROSTENT; M.I. Tech, Korea) was placed, which led to clinical resolution of the stenosis at 3-month follow-up and progressive weight gain in the patient. The stent later was removed and the patient's clinical course was positive.

\section{Conclusions}

Extensive ESD is associated with a high risk of stenosis [1-3]. At the gastric level, high rates of stenosis are seen in patients who have undergone ESD that affects $75 \%$ or more of the circumference in the cardia or antrum/pylorus [2,3]. Because of this, prophylactic measures are recommended in these cases [1-4]. The type of stent described can be useful for treatment of a short stenosis that occurs after circumferential ESD and has failed to respond to conventional techniques such as balloon dilation. 
The authors declare that they have no conflict of interest.

The authors

David Barquero Declara, Alfredo Mata Bilbao, Alex Blasco Pelicano

Hospital de Sant Joan Despí Moisès Broggi Gastroenterology, Barcelona, Spain

\section{Corresponding author}

\section{David Barquero Declara}

Hospital de Sant Joan Despí Moisès Broggi Gastroenterology, Calle Jacinto Verdaguer, 90 Sant Joan Despi, 08970 Barcelona, Spain Fax: + 34935531200

david.barquerodeclara@sanitatintegral.org

\section{References}

[1] Hayashi T, Kudo SE, Miyachi H et al. Management and risk factor of stenosis after endoscopic submucosal dissection for colorectal neoplasms. Gastrointest Endosc 2017; 86: 358-369

[2] Sumiyoshi T, Kondo H, Minagawa T et al. Risk factors and management for gastric stenosis after endoscopic submucosa dissection for gastric epithelial neoplasm. Gastric.Cancer 2017; 20: 690-698

[3] Yamamoto Y, Kikuchi D, Nagami Y et al. Management of adverse events related to endoscopic resection of upper gastrointestinal neoplasms: review of the literature and recommendations from experts. Dig Endosc 2019; 31: 4-20

[4] Shibagaki k, Yuki T, Taniguchi H et al. Prospective multicenter study of the esophagel triamcinolone acetonide-filling method in patients with subcircumferential esophageal endoscopic submucosal dissection. Dig Endosc 2020; 32: 355-363

\section{Bibliography}

DOI http://dx.doi.org/10.1055/a-1230-3790 Endoscopy International Open 2020; 08: E1582E1583

Georg Thieme Verlag KC

Rüdigerstraße 14 ,

70469 Stuttgart, Germany

elSSN 2196-9736

(c) 2020. The Author(s).

This is an open access article published by Thieme under the terms of the Creative Commons Attribution-NonDerivative-NonCommercial License, permitting copying and reproduction so long as the original work is given appropriate credit. Contents may not be used for commecial purposes, or adapted, remixed, transformed or built upon. (https://creativecommons.org/licenses/by-nc-nd/4.0/)

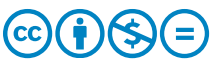

